\title{
OPTIMAL RETROFIT SELECTION FOR SEISMICALLY-DEFICIENT RC BUILDINGS BASED ON SIMPLIFIED PERFORMANCE ASSESSMENT
}

\author{
Roberto Gentile $^{1}$, and Carmine Galasso ${ }^{1}$ \\ ${ }^{1}$ Department of Civil, Environmental and Geomatic Engineering \& \\ Institute for Risk and Disaster Reduction, University College of London \\ Gower St., London, United Kingdom \\ e-mail: \{r.gentile, c.galasso\}@ucl.ac.uk
}

\begin{abstract}
This study deals with the selection of optimal retrofit solutions for seismically-deficient Reinforced Concrete (RC) buildings. To this aim, Multi-Criteria Decision-Making (MCDM) analysis is used. A discussion on the retrofit design strategy is first presented, recommending designing each retrofit solution for the same expected damage state under the design-level earthquake-induced ground-motion spectrum. Secondly, it is argued to explicitly consider seismic economic losses as a decision criterion. To this aim, seismic fragility/vulnerability relationships are derived for the structure of interest retrofitted with different techniques and considering a large suite of ground-motion records. Simplified-yet-accurate non-linear static procedures are used as an alternative to non-linear time-history analysis to reduce the challenges in building detailed numerical models, computational demand, and results interpretation. Specifically, three increasingly-refined structural analysis methods are adopted to derive fragility/vulnerability curves: the Simple Lateral Mechanism Analysis (SLaMA), which is an analytical approach; numerical pushover; and non-linear time-history analysis. A seismicallydeficient RC school index building, with construction details typical of developing countries, is used for illustrative purposes. The case-study structure is retrofitted through concrete jacketing, addition of concrete walls, and addition of steel braces, all designed through Direct Displacement-Based Design. The MCDM analysis is performed adopting, among other criteria, intensity-based losses derived with the three considered analysis methods, using state-of-theart, advanced ground-motion intensity measures. The results show that the ranking of the retrofit alternatives is rather insensitive to the adopted analysis method, even if the considered weight for the seismic loss criterion is relatively high (30\% in this example). Findings from this study suggest that simplified analysis methods can be effectively employed in the preliminary/conceptual design of retrofit solutions for seismically-deficient buildings.
\end{abstract}

Keywords: Reinforced Concrete, seismic performance assessment, time-history, pushover, SLaMA, seismic retrofit, multi-criteria decision making. 


\section{INTRODUCTION}

In earthquake-prone regions, the seismic capacity of existing structures is often inadequate to sustain the expected earthquake demand. In fact, most of the existing buildings is designed according to pre-seismic codes (i.e., they are under-designed). For communities aiming to achieve seismic resilience (i.e., the ability to recover quickly after an earthquake), increasing seismic structural performance is especially important. Structural retrofit is an effective strategy to achieve this, by reducing physical fragility and vulnerability of the considered structures.

Seismic fragility is quantitatively expressed as the conditional probability that a structure will reach or exceed a specified level of damage (or damage state, DS) for a given value of a considered ground-motion intensity measure (IM). Fragility relationships describe such conditional probability for increasing values of the ground-motion IM, taking the form of cumulative distribution functions (CDFs). Vulnerability relationships, on the other hand, express continuous relationships between the IM and the probability distribution (mean and variability) of consequences/loss, expressed for instance by means of the repair-to-reconstruction cost ratio (loss ratio).

When dealing with seismic retrofit of under-designed structures, the effective reduction of seismic fragility (and, in turn, of seismic risk) should play a major role. For a desired reduction of the fragility/risk, the optimal decision among many retrofit strategies/techniques available in the common practice [1] is usually based on various criteria, such as the cost of the retrofit solution, the duration of the works, etc.

Multi-Criteria Decision-Making (MCDM) analysis represents an effective tool supporting decisions, allowing a Decision Maker (DM) to select the (often conflicting) criteria that will drive the decision, and quantitatively define the relative importance of each of them according to his/her subjective preferences. This allows to systematically compare alternatives based on the selected criteria and their relative weights. Moreover, MCDM can provide enough flexibility to deal with subjective decisions that can depend on the personal preferences of the DM, social/political constraints, etc.

The selection of the optimal seismic retrofit solution among two or more alternatives on the basis of a finite number of criteria is a Multiple-Attribute Decision-Making (MADM) problem, a subset of the MCDM approaches. Examples of those are:

- the weighted sum model [2];

- the weighted product model $[3,4]$;

- the ELimination Et Choix Traduisant la REalité, or ELECTRE [5];

- the Multi-Attribute Utility Theory, or MAUT [6];

- the Preference Ranking Organization METHod for Enrichment Evaluations, or PROMETHEE [7];

- the VIseKriterijumska Optimizacija I KOmpromisno Resenje, or VIKOR [8];

- the Analytic Hierarchy Process, or AHP [9];

- the Technique for Order Preference by Similarity to Ideal Solution, or TOPSIS [10].

The relevant literature indicates that no single approach is generally superior, and the selection of a method depends on the specific problem. Among those methods, the joint adoption of the TOPSIS and the AHP is deemed to be the best option for MADM problems [11], since those provide a complete ranking of each considered alternative in each criterion, and require the minimum number of parameters fixed by the DM.

Firstly, the relative importance of each criteria (weights) is determined with the AHP. This is a mathematical procedure that reduces such a complex decision to a series of one-on-one comparisons among the criteria, providing a clear rationale for the decision. Therefore, each alternative solution is provided with a score (quantitative or qualitative) in each of the selected 
criteria, which are normalised and weighted. According to the TOPSIS procedure, the optimal retrofit alternative is defined as the one having the shortest Euclidean distance from an ideal solution, which is defined using the maximum score for each criterion.

The suitability of such approach for retrofit selection problems has been confirmed in [12] and [13], which provide solid methodological grounds for the application of the method to this problem. In those studies, MCDM is applied for the selection of the optimal retrofit solution for a case-study RC building. However, several simplifying working assumptions are used by the authors. For instance, the seismic capacity of the case-study building is calculated in terms of Peak Ground Acceleration (PGA), based on a pushover analysis and a code-based elastic spectrum. The seismic risk is defined as the exceeding probability of such capacity PGA, according to a code-based hazard curve. More importantly, the seismic performance is not controlled in the retrofit design, leading to solutions resulting in different design (nominal) DS for the same value of the ground motion IM. To account for such differences, seismic risk is explicitly considered as a criterion in the MCDM.

An attempt to address these shortcomings is presented in this paper. Firstly, it is proposed to design different retrofit solutions according to the Direct Displacement-Based Design (DDBD, [14]), to ensure the same nominal DS for a given seismic demand (i.e., performance-based approach is used). In turn, this allows to remove the nominal seismic performance from the MCDM criteria. On the other hand, intensity-based loss (expressed in terms of repair-to-reconstruction cost ratio) is instead considered as a criterion, since such a parameter is deemed to be fundamental in a modern design that goes beyond the life safety performance. Moreover, it is proposed to calculate the seismic fragility/vulnerability for the different retrofit solutions considering a large suite of unscaled, real (i.e., recorded during past events) ground-motions records, rather than using smooth (and conservative) code spectra. Usually, this requires running a refined numerical time-history analysis for each selected ground motion to build a probabilistic seismic demand model (e.g., through cloud-based or incremental dynamic analysis procedures) and derive fragility and vulnerability curves (through ad-hoc damage-to-loss ratios). It is recognised, however, that the required computational effort (and modelling needs) for timehistory analysis might be unjustified at such a preliminary/conceptual retrofit design phase in which many retrofit solutions might be tested.

Based on this discussion, it is proposed here to use less complex structural analysis methods as an alternative to non-linear time-history analysis. In particular, force-displacement curves are derived using both numerical pushover analyses and the Simple Lateral Mechanism Analysis (SLaMA, analytical approach). The Capacity Spectrum Method (CSM, [15]), adopting the considered suite of real records, is applied using such curves, therefore deriving fragility and vulnerability curves that are, in turn, an input to the MCDM analysis.

The proposed framework for optimal retrofit selection is demonstrated for a seismicallydeficient Reinforced Concrete (RC) school index building, with construction details typical of developing countries in Southeast Asia, for which real field-data is available. Three retrofit solutions are analysed: RC column jacketing, addition of RC walls, addition of steel braces. The above-mentioned simplified methods are independently adopted to carry out the MCDM analysis. As a benchmark case, the more refined time-history approach is also adopted.

\section{METHODOLOGY}

The first step in this study is the seismic performance analysis of the as-built configuration of the selected case-study building. Consequently, the three different retrofit configurations (RC jacketing, addition of RC walls, addition of steel braces) are designed to withstand the designlevel seismic demand, resulting in the same expected damage level (performance-based approach). Structural analyses are hence conducted according to non-linear time-history analyses, 
pushover analysis and SLaMA approach (Section 2.1) to independently derive a cloud of points in the Engineering Demand Parameter (EDP) vs Intensity Measure (IM) space. The obtained cloud is finally used to derive fragility and vulnerability curves.

The optimal retrofit solution is selected according to the MCDM approach (Section 2.2). As discussed above, intensity-based economic loss is considered among the adopted criteria for the MCDM. The final objective of the work is to apply the proposed MCDM scheme independently using the loss calculated with the three methods, analysing the sensitivity of the final retrofit choice to the refinement of the structural analysis method.

\subsection{Assumptions for the structural analyses}

Maximum inter-storey drift (i.e., maximum -over all stories- peak inter-storey drift) is the selected EDP; it is a convenient proxy to represent structural and non-structural building damage, because it is highly correlated with damage and repair costs. The selected IM is defined as the geometric mean $(A v g S A)$ of the pseudo-spectral acceleration in the interval $\left[0.2 \mathrm{~T}_{1}, 2 \mathrm{~T}_{1}\right]$, where $T_{1}$ is the elastic period of the building (as-built or retrofitted). This ensures increased efficiency and sufficiency in estimating a given EDP by means of a scalar IM [16,17]. 150 unscaled natural ground motions are selected from the SIMBAD database (Selected Input Motions for displacement-Based Assessment and Design, [18]). As in [19], these records are selected by first ranking the 467 records in terms of their PGA values (by using the geometric mean of the two horizontal components) and then (arbitrarily) keeping the component with the largest PGA value. The EDP for each ground motion is defined with three different methods.

Non-linear time-history analyses are firstly conducted for a refined numerical model defined using the FEM software Ruaumoko [20]. The modelling strategy (Figure 1) is based on a lumped plasticity approach capable of predicting flexural, bar slip and shear failure of RC beams and columns, together with shear failure in the beam-column joints and strength degradation (details can be found in [21]). Separate two-dimensional analyses are conducted for the transverse and longitudinal directions of the case-study building.

The same numerical model has been adopted for pushover analyses, to derive force-displacement curves. The CSM [15] is applied to calculate the maximum inter-storey drift for each natural ground motion and derive EDP vs IM pairs. Finally, the Simple Lateral Mechanism Analysis (SLaMA, $[22,23,24,25,26])$ is adopted to derive a force-displacement capacity curve and the expected plastic mechanism. The analytical, "by-hand", method is briefly resumed in Figure 2. Again, the CSM is adopted to derive the EDP vs IM clouds.

The linear least square method is applied on the derived (EDP, IM) pairs, estimating the conditional mean and standard deviation of EDP given IM and deriving the commonly-used power-law model $E D P=a I M^{b}$, where $a$ and $b$ are the parameters of the regression. The derived probabilistic seismic demand model is used to define the median $(\mu)$ of four lognormal fragility curves, one for each DS, and the corresponding logarithmic standard deviation $\beta$ (which is the same the four curves, due to the homoskedasticity assumptions in the cloud approach). 

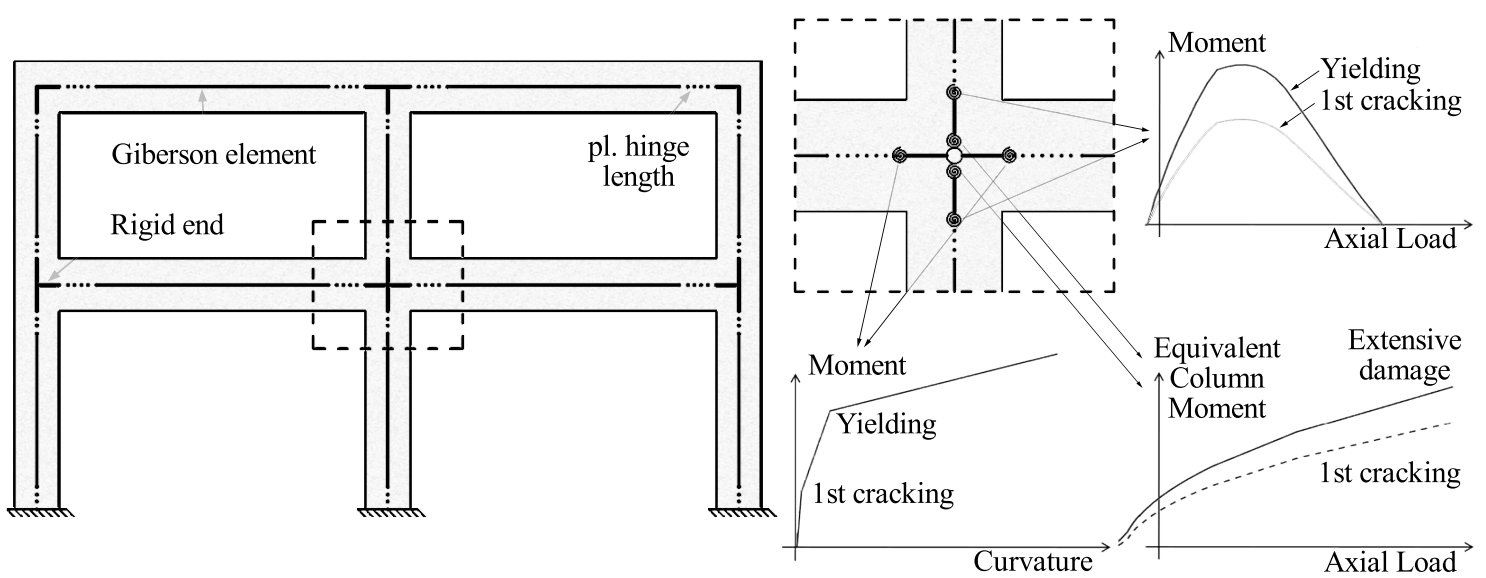

Figure 1: Numerical modelling strategy (adapted from Gentile et al., 2019a).

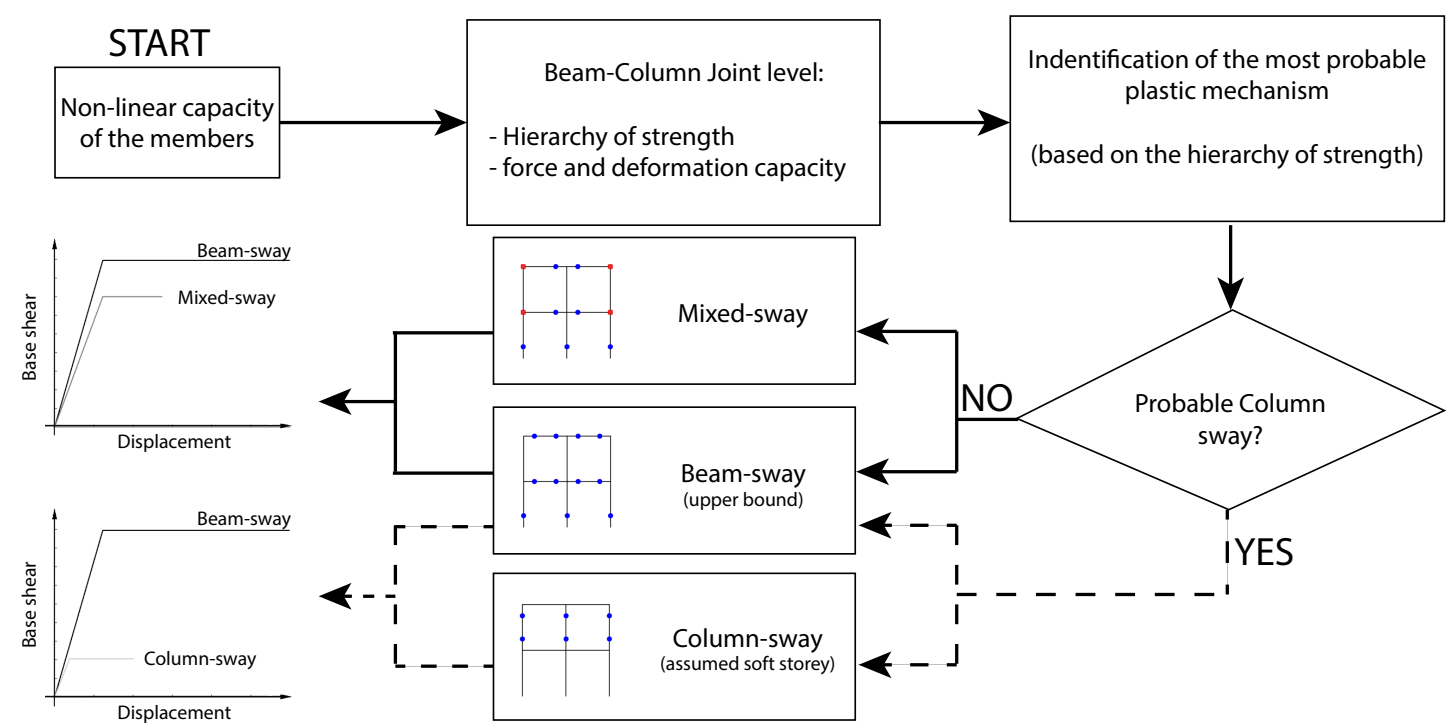

Figure 2: Overview of SLaMA [23].

\subsection{Multi-Criteria Decision Making (MCDM)}

Each adopted retrofit technique can be evaluated according to different criteria, which may give different perspectives to the same technical solution. Table 1 shows the seven adopted criteria, which are deemed to be appropriate ones for interventions on public schools [27], and possibly in line with the preferences of a government agency (e.g., Department of Education). The same table shows the weights assigned to each criterion, which represent their relative importance according to the DM. To have a rational and mathematically-consistent definition of the weights, the AHP [9] is adopted. According to this procedure, the user expresses an opinion on every possible pairwise comparison among the criteria (in this case, 21 comparisons, Table 1). Each of those is a linguistic phrase that is subsequently converted into a number between one and nine. If parameters $j$ and $k$ are equally important, a value of 1 is assigned; if $j$ is demonstratedly more important than $k$, a value of 7 is assigned; if $k$ is essentially more important than $j$, a value of $1 / 5$ is assigned. Finally, the first eigenvalue of this so-called decision matrix is manipulated to obtain the desired weights. Further details on the weight calibration can be found in [12]. 


\begin{tabular}{|c|c|c|c|c|c|c|c|c|}
\hline weight & Criterion & 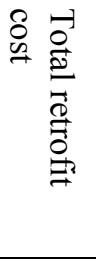 & 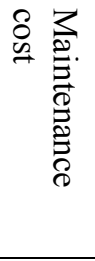 & 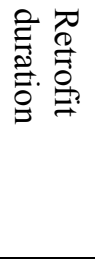 & 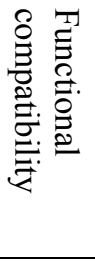 & 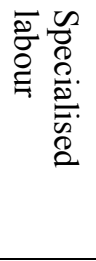 & 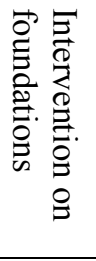 & $\begin{array}{l}5 \\
0 \\
0 \\
\infty \\
00 \\
0 \\
0 \\
0 \\
0 \\
0\end{array}$ \\
\hline 0.306 & Total retrofit cost & 1 & 9.000 & 9.000 & 3.000 & 8.000 & 2.000 & 1.000 \\
\hline 0.032 & Maintenance cost & 0.111 & 1 & 1.000 & 0.250 & 1.000 & 0.167 & 0.111 \\
\hline 0.032 & Retrofit duration & 0.111 & 1.000 & 1 & 0.250 & 1.000 & 0.167 & 0.111 \\
\hline 0.109 & Functional compatibility & 0.333 & 4.000 & 4.000 & 1 & 3.000 & 0.500 & 0.333 \\
\hline 0.035 & Specialised labour & 0.125 & 1.000 & 1.000 & 0.333 & 1 & 0.200 & 0.125 \\
\hline 0.180 & Intervention on foundations & 0.500 & 6.000 & 6.000 & 2.000 & 5.000 & 1 & 0.500 \\
\hline 0.306 & Loss (scenario-based) & 1.000 & 9.000 & 9.000 & 3.000 & 8.000 & 2.000 & 1 \\
\hline
\end{tabular}

Table 1: Input for the MCDM, assuming a government agency as the DM.

The evaluation of each retrofit solution according to the different criteria can be either quantitative or qualitative. In the former case, some calculation is usually needed to evaluate a criterion (e.g. calculation of the retrofit costs). Instead, qualitative criteria (e.g. need for specialised labour) should be expressed as numerical values to be adopted in the TOPSIS MCDM. To accomplish this, the AHP can be used expressing the relative performance of each alternative with respect to the considered qualitative criterion. The calculated "weights" are therefore used as numerical evaluation in the TOPSIS. For this study, the approach in evaluating each criterion is summarised as follows:

- Total retrofit cost: for each retrofit alternative, the total costs are calculated as a sum of demolition cost (if needed), the installation cost of the intervention itself (excluding foundations), and the reconstruction of the demolished parts. Costs related to construction site setting and health/safety costs are also considered. Indonesian costs for basic materials and labour are adopted [28] and the final result is converted in US\$;

- Maintenance cost: based on a given frequency of the required maintenance checks, the total cost of maintenance is calculated for a service life equal to 50 years. For RC jacketing and addition of RC walls, an inspection every 5 years (570\$) and an instrumental examination every 10 years $(1700 \$)$ are considered. For the addition of steel bracings, an inspection every 5 years $(570 \$)$ and an anti-corrosive treatment every 20 years $(16000 \$)$ are needed. It is worth mentioning that the prices are based on a market survey, and a revaluation rate equal to $4 \%$ is adopted for the calculation;

- Retrofit duration: for each retrofit alternative, the total time required to carry out a given intervention is calculated; it considers the work phases needed for the interventions, and a number of workers, based on engineering judgement;

- Functional compatibility: This criterion is evaluated based on an AHP calculation expressing the relative invasiveness of each retrofit solution (e.g., RC jacketing is less invasive than the addition of walls or braces). As opposed to the others, this criterion is treated as a benefit, meaning that a higher value of functional compatibility indicates a higher performance;

- Specialised labour: This criterion is evaluated based on AHP calculations. This allows to represent the relatively higher level of labour specialization needed for some of the alternatives (i.e., the addition of the steel braces with respect to RC jacketing or walls addition);

- Intervention on foundations: This criterion is evaluated based on an AHP calculation that considers installation costs, time and specialised labour for the intervention on the foundations. This captures the much higher invasiveness and cost of the foundation for the RC walls addition with respect to steel braces and jacketing; 
- Loss (intensity-based): the values of the repair-to-reconstruction cost ratios are calculated intersecting the vulnerability functions in correspondence of the $\mathrm{AvgSA}$ of the code-based design spectrum in the interval $\left[0.2 \mathrm{~T}_{1}, 2 \mathrm{~T}_{1}\right]$. The average between the two building directions is considered.

The values of each criterion and each retrofit solution $\left(x_{i j}\right)$ are finally processed according to the TOPSIS procedure to produce a final ranking [12]. For each criterion, the evaluations are normalised with respect to the square root of the sum of the squares of all the evaluations for the same criterion. Therefore, each normalised evaluation is multiplied by the weight of the corresponding criterion. Then, the ideal best (worst) solution is defined considering the highest (lowest) evaluation for each criterion. The Euclidean distance of each alternative from the ideal best and worst solutions is calculated. The alternative with the highest distance from the ideal worst solution is the optimal alternative. The final result is normalised in the interval $[0,1]$ for convenience (the best solution has the highest normalised distance from the ideal worst).

\section{ILLUSTRATIVE APPLICATION}

\subsection{Description of the case-study structure and considered retrofit solutions}

The case-study school selected for this study represents seismically-deficient RC school buildings typical of developing countries such as Philippines and Indonesia. In fact, this building typology is defined based on large data collection exercises (e.g. [29,30]) involving Rapid Visual Surveys for over 200 school buildings and collecting administrative, geometric and mechanical data related to the investigated buildings. The resulting index building is a two-storey, ten-bay by three-bay rectangular framed building, representing approximately the $80 \%$ of the surveyed schools. Figure 3 indicates its geometrical dimensions, defined as the modal values of the statistical distributions built on the collected data [29].

Although measured data related to structural detailing is not available, two different simulated design approaches are performed to reflect two nominal seismic-performance levels. To this aim, the buildings are simulated designed according to the Uniform Building Code (UBC) [31] and the American Society of Civil Engineers (ASCE) 7-10 [32]. In fact, building codes in developing countries are often inspired by the UBC and/or the United States codes [29,30]. However, some of the provisions in such codes have not been applied in the simulated design (e.g. stirrups in the joints) to somehow take into account the possibility of lack of code enforcement, based on the field survey results. The resulting detailing for the two cases (Table 2) leads to a "Pre-Code" and a "Low-Code" configurations, as defined in HAZUS MH4 (HAZard United States, [33]). Acting loads are calculated considering permanent dead loads and live load equal to $5 \mathrm{kPa}$ ( $1 \mathrm{kPa}$ for the roof). A mean steel yield stress equal to $400 \mathrm{MPa}$ has been adopted for longitudinal bars (240MPa for stirrups), while the mean concrete cylindrical strength is equal to $21 \mathrm{MPa}$ and $24 \mathrm{MPa}$ for the Pre-Code and Low-Code configurations. Such values are based on statistical analyses related to Indonesian materials [34].

Three different retrofit solutions - jacketing, walls, braces (Figure 3) - have been designed to achieve moderate damage for the design-level seismic demand calculated according to the ASCE 7-10 (50\% exceeding probability in 50 years). This is defined by first considering the Maximum Considered Earthquake (MCE) and then reducing it by a factor of two-thirds. The MCE is calculated for risk category III (school) and soil type E. By assuming the building located in a high seismic region in Southeast Asia, the spectrum is defined according to the parameters $S_{s}=1.7 \mathrm{~g}$ and $S_{1}=0.7 \mathrm{~g}$ [35], that define the spectral acceleration respectively for 
short and long periods. Such a strict requirement is chosen to have an essentially-elastic structure for the design level earthquake, which can be used as a shelter in the aftermath of an event. With school children being one of the most vulnerable components of the society due to their age and their developmental stage, such a design choice specifically aims at achieving both educational continuity and resilience. The resulting pushover curves (Figure 4), also expressed in a capacity spectrum format, show the effectiveness of the retrofit design. The effective height displacement is adopted in the figure, obtained interpolating the displacement profile of the structure in correspondence to the height of an equivalent single degree of freedom system.

In the jacketed solution, the size of all the columns is increased to $60 \times 60 \mathrm{~cm}$, adopting concrete with mean cylindrical strength equal to $30 \mathrm{MPa}$. $16 \phi 24$ equally-spaced longitudinal reinforcing bars are adopted, along with $\phi 10$ hoops $\left(135^{\circ}\right.$ bent) spaced at $6 \mathrm{~cm}$ in the plastic hinge zones. The mean steel yield stress is equal to $400 \mathrm{MPa}$. For the wall retrofit solution, two $3.3 \mathrm{~m}-$ long walls are provided for each external longitudinal frame. Those are reinforced with 12 equally-spaced longitudinal bars $(\phi 16)$ in the $0.6 \mathrm{~m}$-long confined zone, along with one $\phi 16$ every $14 \mathrm{~cm}$ in the central zone. Moreover, $\phi 14$ stirrups spaced at $10 \mathrm{~cm}$ are provided. Four frames in the transverse direction, are equipped with a $3.9 \mathrm{~m}$-long wall, which is reinforced in the same fashion. Finally, the configuration of the braces in the last retrofit solution is shown in Figure 3, those are provided for two longitudinal and four transverse frames. The braces have an "X" cross section with $10 \mathrm{~cm}$ side and $1.5 \mathrm{~cm}$ thickness (composed by four Angle profiles). S235 structural steel (with minimum yield stress equal to $235 \mathrm{MPa}$ ) is adopted for the braces. It is worth mentioning that the same retrofit specifications are used for both the Pre-Code and Low-Code building configurations, as resulted from the DDBD calculations.

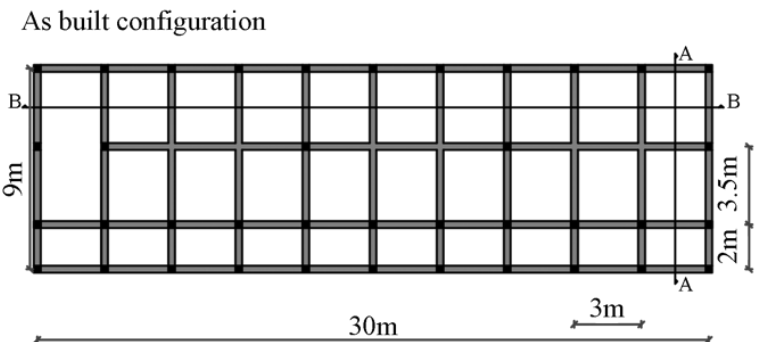

Jacketing configuration

Wall configuration
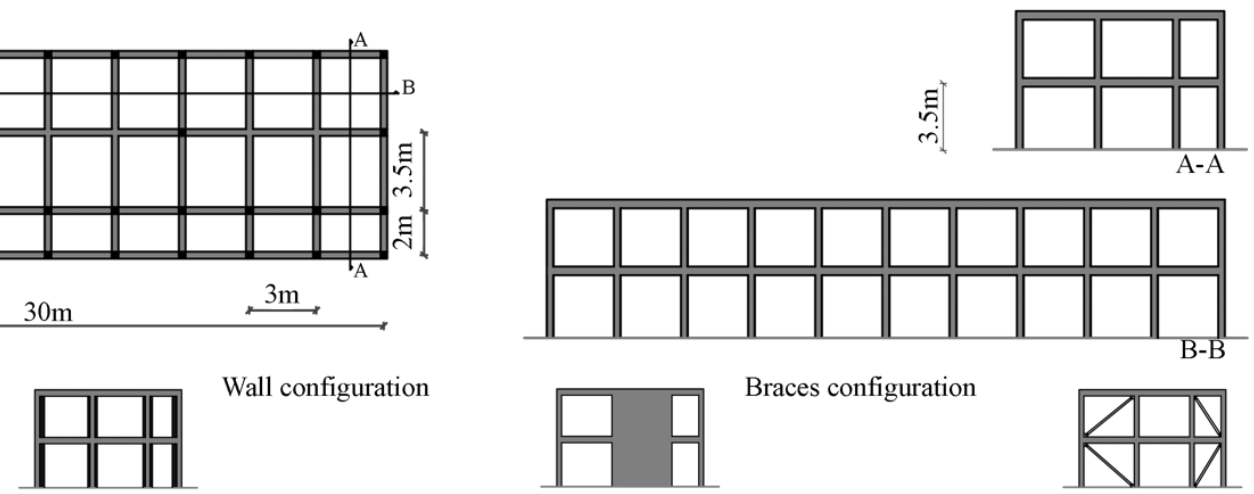

Braces configuration
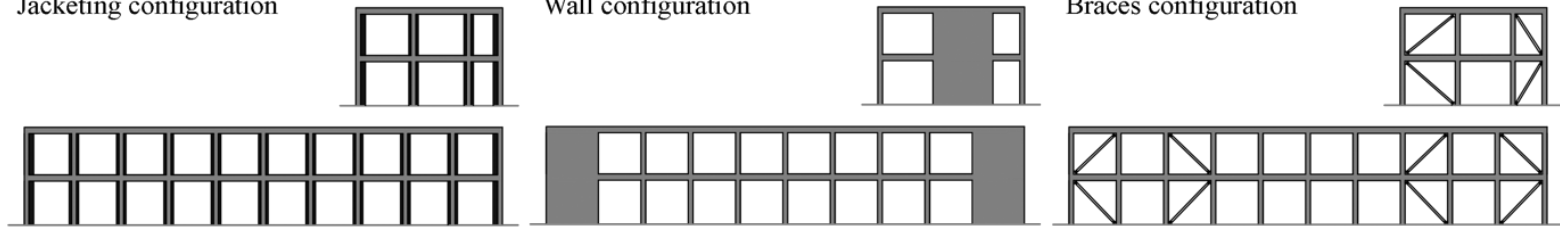

Figure 3: As built and retrofitted configurations for the index building(s).

\begin{tabular}{llll}
\hline & Beams (typical) & Columns (typical) & Joints \\
\hline Pre-Code & $3 \phi 16$ top & $3 \phi 16$ top & No stirrups \\
& $3 \phi 16$ bottom & $3 \phi 16$ bottom & \\
Low-Code & $\phi 10 @ 150 \mathrm{~mm}$ stirrups & $\phi 10 @ 200 \mathrm{~mm}$ stirrups & \\
& $3 \phi 16$ top & $3 \phi 16$ top & No stirrups \\
& $3 \phi 16$ bottom & $3 \phi 16$ bottom & \\
$\phi 10 @ 150 \mathrm{~mm}$ stirrups & $\phi 10 @ 100 \mathrm{~mm}$ stirrups & \\
\hline
\end{tabular}

Table 2: Structural details for the as-built configuration. 

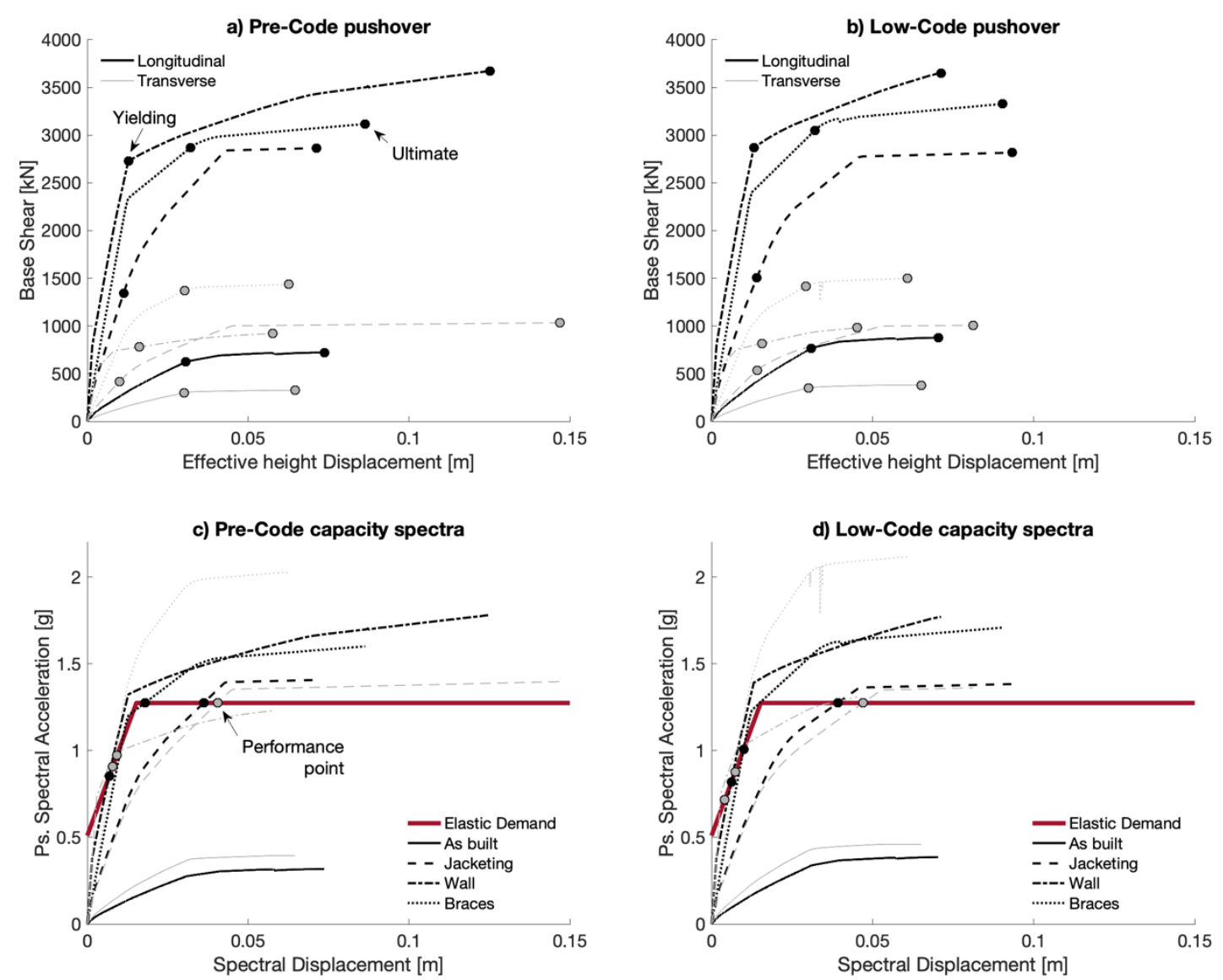

Figure 4: Pushover curves $(a, b)$ and capacity spectra $(c, d)$ for each retrofit solution.

\subsection{Results}

As mentioned in Section 2.1, each building configuration (Pre-code, Low-code) in each configuration (as-built, jacketing, wall, braces) is analysed with three analysis methods with an increasing level of refinement. As an example, Figure 5 shows the transverse fragility analysis of the Pre-Code building retrofitted with jacketing. Firstly, it is clear that up to the attainment of DS4, the SLaMA-based capacity curve agrees with the pushover curve with minor discrepancies (Figure 5a). For higher displacements, strength degradation occurs, which is not considered in SLaMA. The good match in the capacity curves is reflected in the inter-storey drift vs geometric mean of spectral acceleration cloud (Figure 5b).
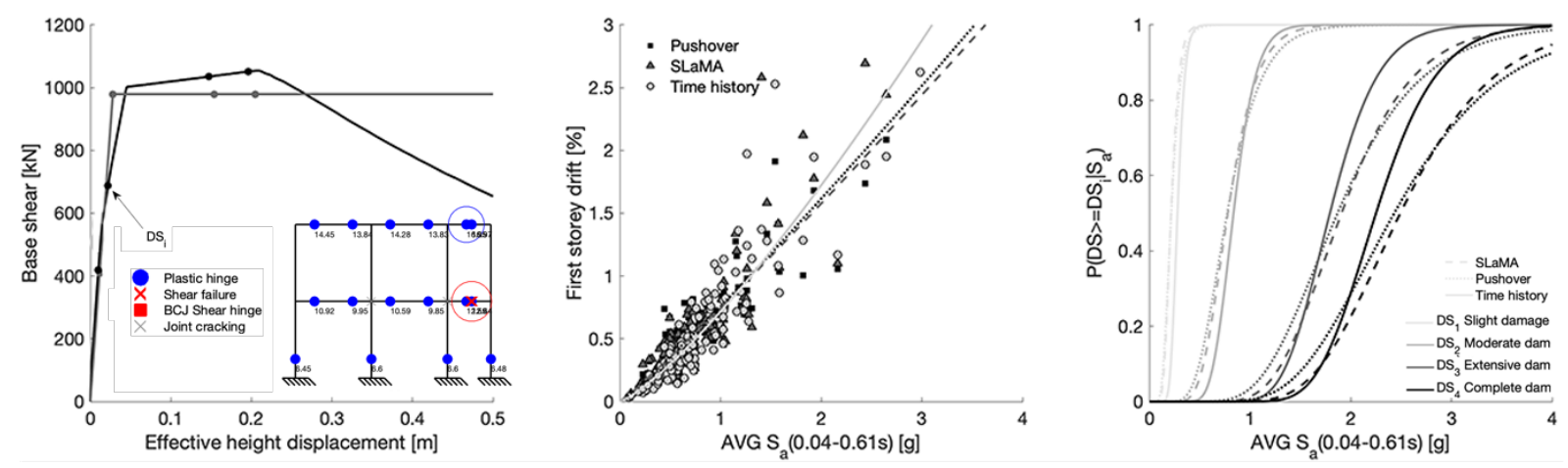

Figure 5: Comparison of the different analysis approaches for the "Pre-Code" building with jacketing. 
The performance points obtained with the CSM for the set of real records, both based on SLaMA and numerical pushover, are in agreement with the results of the non-linear time-history analyses. In turn, these similarities are reflected in the obtained fragility curves (Figure 5c), calculated for four configuration-specific drift limits, consistent with four DSs.

The obtained fragilities are adopted to calculate vulnerability curves, by considering damage-to-loss ratio appropriate for each DS. As a starting point, the repair-to-reconstruction ratios for schools proposed in HAZUS are considered, which are equal to $2 \%, 10 \%, 43.5 \%$ and $100 \%$ for increasing DSs. Generally, a regional modification factor should be applied to consider the specific cost data related to developing countries; in this case Philippines or Indonesia. However, according to the Prompt Assessment of Global Earthquakes for Response (PAGER) [36,37] for Modified Mercalli Intensity (MMI) values greater than 8 (reasonable assumption for the considered countries), it is possible to assume a regional modification factor equal to one.

Figure 6 shows the vulnerability curves calculated for each analysed configuration, in each building direction and adopting the three analysis methods. The code spectrum is adopted to define, for the ranges of periods shown in the figure, the average spectral acceleration demand. For such intensity level, the relative error on the seismic vulnerability is below $17 \%$ and $20 \%$ respectively for pushover and SLaMA, for the majority of the case studies. Clearly, such results are not general nor generalisable yet. Systematic research is needed to estimate the bias of the SLaMA- and pushover-based method in estimating the median and dispersion of the fragility curves with respect to the time-history approach, which in turn affects vulnerability estimates. However, the results are promising, and they suggest that efforts should be made to better calibrate simplified methods to derive fragility curves, e.g. CSM adopting real ground motions.
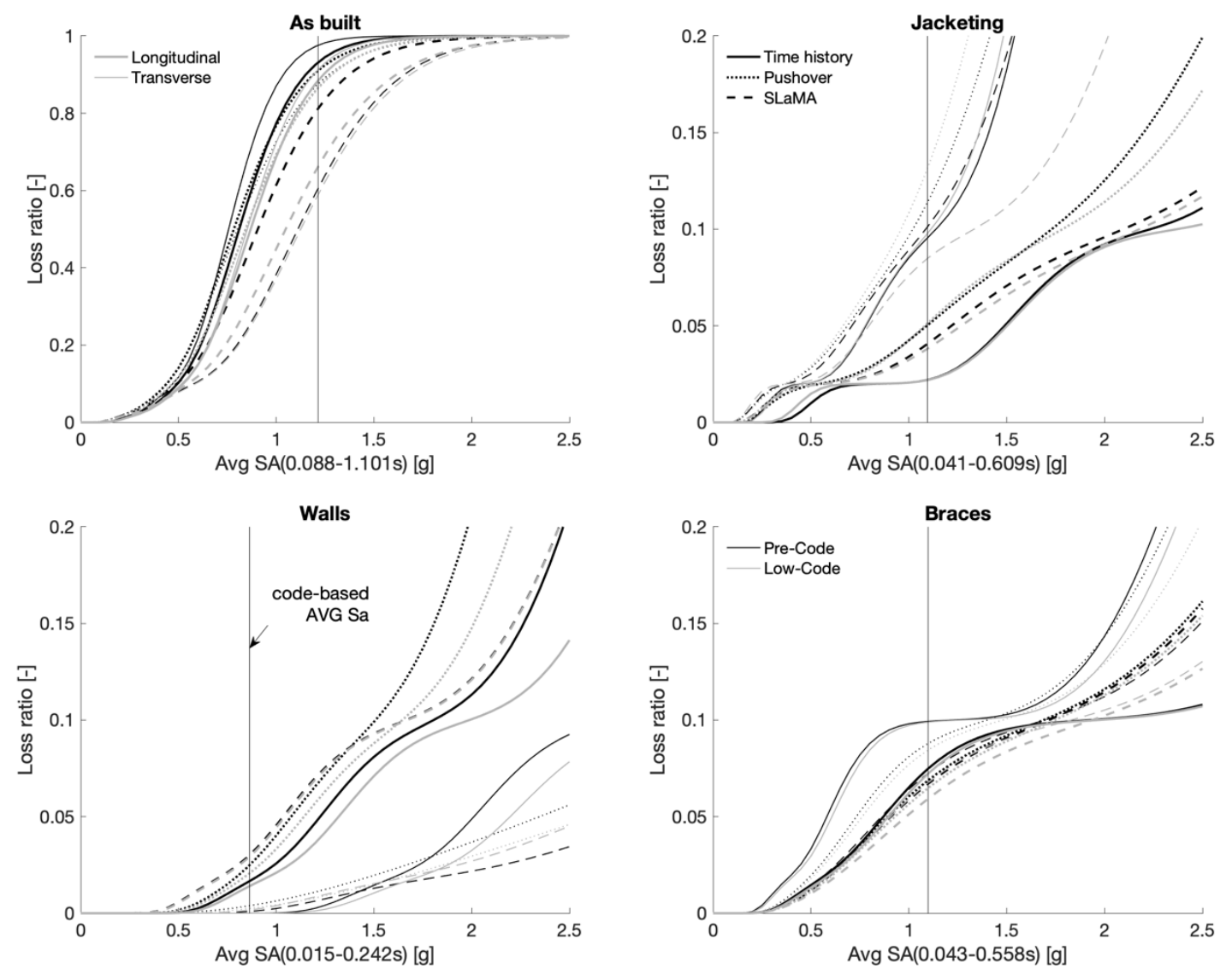

Figure 6: Vulnerability curves for each retrofit solution and analysis method. 
The last step of the procedure is to carry out the MCDM to select the optimal retrofit solution for this specific case study, according to the specifications in Section 2.2. Table 3 shows the performance of the retrofit solutions calculated for each of the selected criteria (the loss ratio is based on the time-history approach). On the other hand, Table 4 shows the results of the MCDM, i.e. the ranking of each retrofit solution in terms of both overall and criterion-specific performance. According to this analysis, the wall retrofit solution is judged as optimal, followed by the bracing solution and the jacketing.

Such a result reflects the relative importance of the installation cost and the intensity-based losses (each of these representing 30\% of the weight). In particular, jacketing is the worst solution since, being a global intervention, its installation cost is one order of magnitude higher than the other two solutions (local interventions). Between the remaining two alternatives, the loss ratio for the bracing solution is approximately three times higher than the wall solution, and therefore the braces alternative is ranked second. Finally, the wall solution has the highest performance, even if it requires a more invasive and expensive intervention on foundations (18\% weight).

\begin{tabular}{|c|c|c|c|c|c|c|c|}
\hline & 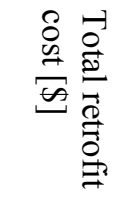 & 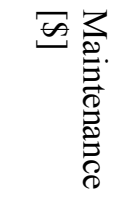 & 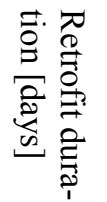 & 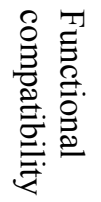 & 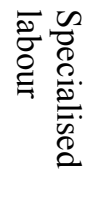 & 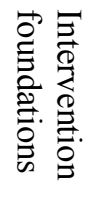 & 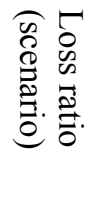 \\
\hline Wall & 93929 & 40353 & 29 & 0.238 & 0.570 & 0.714 & 0.031 \\
\hline Jacketing & 381814 & 40353 & 120 & 0.641 & 0.321 & 0.143 & 0.078 \\
\hline Braces & 82945 & 115602 & 73 & 0.121 & 0.109 & 0.143 & 0.094 \\
\hline
\end{tabular}

Table 3: MCDM decision matrix for the "Pre-Code" case study.

\begin{tabular}{|c|c|c|c|c|c|c|c|c|}
\hline & 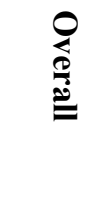 & 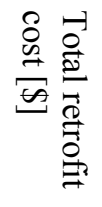 & 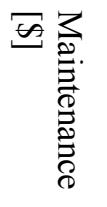 & 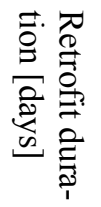 & 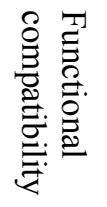 & 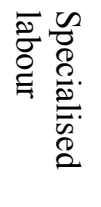 & 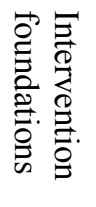 & 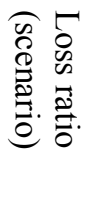 \\
\hline Wall & 0.674 & 0.072 & 0.010 & 0.006 & 0.037 & 0.030 & 0.173 & 0.023 \\
\hline Braces & 0.524 & 0.063 & 0.029 & 0.016 & 0.019 & 0.006 & 0.035 & 0.252 \\
\hline Jacketing & 0.396 & 0.291 & 0.010 & 0.027 & 0.100 & 0.017 & 0.035 & 0.173 \\
\hline
\end{tabular}

Table 4: Ranking of the retrofit solutions (losses based on $\mathrm{TH}$ ).

The final goal of this paper is to investigate the possibility of using simplified but accurate methods to include fragility/vulnerability estimations in the decision process. Therefore, the MCDM is repeated twice, independently considering the loss ratios calculated by means of the pushover and the SLaMA. Table 5 shows the results of such sensitivity analysis: although the weight for the seismic losses criterion is approximately equal to $30 \%$, the ranking of the retrofit alternatives is rather insensitive to the adopted analysis method. This seems to suggest that for such a preliminary phase of the retrofit design, refined numerical methods can be effectively replaced by simplified methods without losing accuracy in the results.

Some interesting trends are observed, and further investigation is deemed to be required. The pushover- and SLaMA-based rankings are particularly similar, and slightly biased with respect to the time-history approach. Such discrepancies can be traced back to the determination of the fragility functions. Moreover, since the force-displacement curves according to SLaMA and the 
pushover are particularly similar, the error on the fragilities can be related to the adoption of the CSM with real records. It is evident that a refinement/calibration of such method could improve the overall accuracy, e.g. adopting FRACAS (FRAgility through Capacity spectrum Assessment [19]).

\begin{tabular}{llllll}
\hline \multicolumn{2}{c}{ Time-history } & \multicolumn{2}{c}{ Pushover } & \multicolumn{2}{c}{ SLaMA } \\
\hline Wall & 0.674 & Wall & 0.658 & Wall & 0.643 \\
Braces & 0.524 & Braces & 0.596 & Braces & 0.593 \\
Jacketing & 0.396 & Jacketing & 0.350 & Jacketing & 0.364 \\
\hline
\end{tabular}

Table 5: Sensitivity of the ranking with respect to the analysis method.

\section{FINAL REMARKS}

This paper deals with the selection of the optimal retrofit solutions for seismically-deficient buildings. The study adopts a MCDM approach to rank different alternatives using a number of criteria selected by a decision-maker. Firstly, it is proposed to exclude seismic performance from the considered criteria in the decision-making, i.e. each retrofit solution should be designed for the same expected damage state under the design-level earthquake. Secondly, it is also proposed to explicitly consider seismic economic loss among the other criteria chosen by the DM. Moreover, it is proposed to calculate the seismic fragility/vulnerability of the different retrofit solutions considering a large suite of unscaled, natural ground motions, rather than using the code spectrum.

It is recognised, however, that the proposed framework may require very high computational effort, together with the structural modelling burden and the consequent interpretation of the analysis results, if non-linear time-history analyses are to be adopted to derive fragility curves. For this reason, it is proposed to use less-complex structural analysis methods as an alternative. In particular, force-displacement curves are derived using both numerical pushover analyses and SLaMA. The CSM, adopting a large suite of natural ground motions, is applied using such curves, therefore deriving fragility and vulnerability curves that are, in turn, an input of the MCDM analysis.

Such method is demonstrated for a seismic-deficient RC school index building, with construction details typical of developing countries (such as Philippines and Indonesia), for which real data is available. Three retrofit solutions are analysed: RC column jacketing, addition of $\mathrm{RC}$ walls, addition of steel braces. A sensitivity of the ranking of the solutions is conducted by repeating the MCDM using loss-ratios calculated by means of non-linear time histories, pushover or SLaMA. Clearly, a certain degree of error is registered in estimating fragility/vulnerability with respect to refined time-history analysis. Nonetheless, for the analysed case study and analysis methods, the ranking of the retrofit alternatives is insensitive to the adopted analysis method, even if the considered weight for the seismic losses criterion is relatively high $(30 \%$ in this example).

These results, although based on a limited case study, seem to indicate that simplified structural analysis methods can represent a tool to effectively include seismic vulnerability (and hence economic losses) in the optimal retrofit selection for seismic-deficient buildings.

\section{ACKNOWLEDGEMENTS}

This study was performed in the framework of the "INSPIRE: INdonesia School Programme to Increase REsilience" and " $i$-RESIST: Increasing REsilience of Schools in Indonesia to earth- 
quake Shaking and Tsunami" projects, funded by the British Council through the Newton Institutional Links scheme and Research England through the UCL Global Challenges Research Fund (GCRF) Small Research Grants scheme. Costanza Valentini and Claudio Gjoni are gratefully acknowledged for their support in the MCDM exercise.

\section{REFERENCES}

[1] S. Sugano, State-of-the-art in techniques for rehabilitation of buildings, in Proceedings of the 11th World Conference on Earthquake Engineering, Acapulco, Mexico, 1996.

[2] P. C. Fishburn, Additive Utilities with Incomplete Product Set: Applications to Priorities and Assignments, Operations Research Society of America, Baltimore, MD, 1967.

[3] P. W. Bridgman, Dimensional Analysis, Yale University Press, New Haven, CT, 1922.

[4] D. W. Miller, M. K. Starr, Executive Decisions and Operation Research, Prentice-Hall, Inc, Englewood Cliffs, NJ, 1969.

[5] R., Benayoun, B. Roy, N. Sussman, Manual de Reference du programme electre, Mote de Synthese et Formaton, No. 25, Direction Scientifique SEMA, Paris, France, 1966.

[6] W. Edwards, J. R. Newman, Multiattribute Evaluation, Sage Publications Inc., Los Angeles, California, 1982.

[7] J. P. Brans, P. Vincke, A preference ranking organization method (The PROMETHEE method for multiple criteria decision making), Management Science, 31(6), 647- 56, 1985.

[8] S. Opricovic, Multicriteria Optimization of Civil Engineering Systems, Faculty of Civil Engineering, Belgrade, Serbia, 1998.

[9] T. L. Saaty, The analytical hierarchy process: Planning, priority setting, resource allocation. London: McGraw-Hill, 1980.

[10] C. L. Hwang, K. Yoon, Multiple attribute decision making, in Lecture Notes in Economics and Mathematical Systems 186, Springer-Verlag, Berlin, Germany, 1981.

[11] R.V. Rao, J.P. Davim, A decision-making framework model for material selection using a combined multiple attribute decision-making method. International Journal of Advanced Manufacturing Technology, 35: 751, 2008.

[12] N. Caterino, I. Iervolino, G. Manfredi, E. Cosenza, Comparative Analysis of Multi-Criteria Decision-Making Methods for Seismic Structural Retrofitting. Computer-Aided Civil and Infrastructure Engineering 24, 432-445, 2009.

[13] N. Caterino, I. Iervolino, G. Manfredi, E. Cosenza, Multi-criteria decision making for seismic retrofitting of RC structure, Journal of Earthquake Engineering, 12, 1-29, 2008.

[14] M. J. N. Priestley, G.M. Calvi, M. Kowalsky, Displacement-Based Seismic Design of Structures. Pavia, Italy: IUSS Press, 2007.

[15] S. . A. Freeman, Development and use of capacity spectrum method. In: Proc. 6th U.S. National Conference on Earthquake Engineering, Seattle, 1998. 
[16] M. Kohrangi, P. Bazzurro, D. Vamvatsikos, A.Spillatura, Conditional spectrum-based ground motion record selection using average spectral acceleration. Earthquake Engineering and Structural Dynamics 46:1667-1685, 2017.

[17] S. Minas, C. Galasso, Accounting for spectral shape in simplified fragility analysis of case-study reinforced concrete frames. Soil Dynamics and Earthquake Engineering 119:91-103, 2019.

[18] C. Smerzini, C. Galasso, I. Iervolino, R. Paolucci, Ground motion record selection based on broadband spectral compatibility Earthquake Spectra, 30 (4), pp. 1427-1448, 2014.

[19] T. Rossetto, P. Gehl, S. Minas, C. Galasso, P. Duffour, J. Douglas, O. Cook, FRACAS: A capacity spectrum approach for seismic fragility assessment including record-to-record variability. Engineering Structures 125:337-348, 2016.

[20] A.J. Carr, RUAUMOKO2D - The Maori God of Volcanoes and Earthquakes. Inelastic Analysis Finite Element program. Carr research 1td, Christchurch, New Zealand, 2016.

[21] C. Del Vecchio, R. Gentile, M. Di Ludovico, G. Uva, S. Pampanin, 2018. Implementation and validation of the Simple Lateral Mechanism Analysis (SLaMA) for the seismic performance assessment of a damaged case study building. Journal of Earthquake Engineering. DOI: $10.1080 / 13632469.2018 .1483278$

[22] NZSEE, New Zealand Society for Earthquake Engineering, The seismic assessment of existing buildings - technical guidelines for engineering assessments. Wellington, New Zealand, 2017.

[23] R. Gentile, C. Del Vecchio, S. Pampanin, D. Raffaele, G. Uva, Refinement and validation of the Simple Lateral Mechanism Analysis (SLaMA) procedure for RC bare frames. Journal of Earthquake Engineering, DOI: 10.1080/13632469.2018.1560377, 2019.

[24] R. Gentile, S. Pampanin, D. Raffaele, G. Uva, Non-linear analysis of RC masonry-infilled frames using the SLaMA method. Part 1: mechanical interpretation of the infill/frame interaction and formulation of the procedure. Bulletin of Earthquake Engineering, DOI: 10.1007/s10518-019-00580-w, 2019.

[25] R. Gentile, S. Pampanin, D. Raffaele, G. Uva, Non-linear analysis of RC masonry-infilled frames using the SLaMA method. Part 2: parametric analysis and validation of the procedure. Bulletin of Earthquake Engineering, DOI: 10.1007/s10518-019-00584-6, 2019.

[26] R. Gentile, S. Pampanin, D. Raffaele, G. Uva, Analytical seismic assessment of RC dual wall/frame systems using SLaMA: Proposal and validation, Engineering structures, DOI: 10.1016/j.engstruct.2019.03.029, 2019.

[27] World bank group, Learning to realize education's promise. World development report, 2018.

[28] Arcadis, 2018. Construction cost handbook Indonesia 2018. Internal report.

[29] A. Nassirpour, C. Galasso, D. D’Ayala, Multi-Hazard Physical Vulnerability Prioritization of School Infrastructure in the Philippines. $11^{\text {th }}$ U.S. National Conference on Earthquake Engineering (11NCEE). Los Angeles, CA, USA, June 25-29, 2018.

[30] R. Gentile, C. Galasso, From rapid visual survey to multi-hazard risk prioritisation and numerical fragility of school buildings. Nat. Hazards Earth Syst. Sci. In press. 2019. 
[31] International Conference of Buildings Officials (ICBO), Uniform Building Code. Whittier, California, USA, 1997.

[32] American Society of Civil Engineers (ASCE), Minimum Design Loads for Buildings and Other Structures. ASCE/SEI Standard 7-10. Reston, Virginia, USA, 2010.

[33] C.A. Kircher, R.V. Whitman, W.T. Holmes, HAZUS Earthquake Loss Estimation Methods". Natural Hazard Review, 7:45-59, 2006.

[34] A. Saputra, Safety Performance of Concrete Structures in Indonesia. Procedia Engineering 171: 985-993, 2017.

[35] Badan Standarisasi Nasional: SNI 1726:2012. Tata cara perencanaan ketahanan gempa unktuk struktur bangunan gedung dan non gedung (in Indonesian). Jackarta, Indonesia, 2012.

[36] K.S.Jaiswal, D.J. Wald, Rapid estimation of the economic consequences of global earthquakes: U.S. Geological Survey Open-File Report 2011-1116, 47 p, 2011.

[37] All Ingegneria, Multi-Hazard Risk Reduction Options for Metro Manila Public School Buildings in support of the Department of Education. World Bank report, 2018. 